\title{
The mitigation potential of eco-taxation on carbon emissions: income effects under downward rigid wages
}

\author{
Ferran Sancho \\ Department of Economics \\ Universitat Autònoma de Barcelona \\ 08193-Bellaterra (Cerdanyola del Vallés), Spain
}

\begin{abstract}
:
Eco-taxation is the preferred market based tool for achieving mitigation of $\mathrm{CO}_{2}$ emissions and fostering sustainability. It works through tax-induced changes in the price of polluting activities while ideally transferring the environmental cost to emitters and users. The initial eco-tax signaling is transmitted and further amplified to the rest of the economy through the structure of cost interactions. In particular, real-world economies work under wage adjustment rules that reflect downward rigidity in labor costs when facing rising prices. These common rules may in fact affect the mitigation capacity of the eco-tax policies. We study this issue using an interindustry model in which we overcome the classical dichotomy between prices and quantities thanks to the novelty of connecting consumption demand with the changes in private income levels that would follow from the enacted eco-tax. We isolate income effects by keeping the given productive structure of the economy as unaltered as possible. In this sense, the proposed model has a bit of a neo-ricardian flavor. We implement the model and check the mitigation effectiveness of two different eco-tax policies using recent tabular data for the Spanish economy in 2015. The main conclusion is that we would not observe double benefits, even when all eco-tax collections are recycled back into the economy.
\end{abstract}

Keywords: Mitigation, eco-taxation, tax recycling, wage adjustment.

\section{Highlights:}

- Eco-tax policies are less effective for carbon mitigation under tax recycling

- More intense wage adjustment rules lessens welfare erosion

- We find no trace of a double dividend

- We incorporate a simple dynamic rule for wage adjustments

- Feedback from prices to quantities achieved using a novel income linkage

JEL codes: C57, Q41, Q52, Q58

Corresponding author: ferran.sancho@uab.cat 


\section{Introduction}

There is a rich body of literature dealing with eco-taxation and its carbon mitigation potential. Since taxation influences resource allocation, general equilibrium methods become the natural analytical tool for policy evaluation. More specifically, computational general equilibrium (CGE) models combine a conceptual modelling platform with background empirical data. They have the distinctive advantage that are able to determine at the same time prices and quantities. These computational models go beyond the private demand and private supply scheme of the theoretical model versions and include descriptive aspects of real-world economies such as government policies and trade issues. The seminal paper of Shoven and Whalley (1985) is still the best description of the essentials and possibilities of these models. See also André et al (2005), Kiuila et al (2019), Freire and Ho (2019) for detailed description of environmental policies using CGE models and Fullerton and Muehlegger (2019) for a discussion of the burden of environmental tax regulations.

From an empirically oriented policy perspective, the CGE approach is usually quite convenient since these methods provide the combined overall effects that are of direct interest to policymakers. At the same time, however, the simultaneous determination of prices and quantities endows the results with a certain degree of opacity. The reason is that it is not easy to separate substitution effects from income effects when comparing two equilibrium states. A possible solution is the use of interindustry models since in them prices and quantities do not interact. See Miller and Blair (2009) for the general theory of interindustry models, and Roland-Holst and Sancho (1995) for a theory of price influence and transmission in this setting. A reinterpretation of these models in Sraffa (1960) offers an inspiring neo-ricardian perspective in price determination and income distribution in private property economies with no trade or government intervention. In this type of pure production economies, with a given and fixed productive structure, prices play the function of ensuring the reproducibility of all flows while maintaining the overall productive structure.

We adopt this reproducible perspective here but we adapt it to an empirically rooted economy with an active government and other sources of final demand, like trade. In actual practice, governments intervene in the economy via taxation and expenditure policies. The combined use of these fiscal tools allows governments to steer the economy towards desirable social or environmental targets. See for instance Bardazzi (1996), Llop and Pié (2008), Gemechu et al (2013), de Souza et al (2016) for specific environmental applications using the interindustry setting.

A critical part often overlooked in price determination is the dynamics of the wage rate in response to price changes. Taxation affects prices and therefore living conditions through the purchasing power of wage income. In any real-world economy, the actual wage rate is the result of many concurrent factors. In particular, of the power of the labor force to negotiate agreements that allow the wage rate to keep its purchasing power, in total or, most often, just in partial terms. The labor market is, possibly, the 
market that stands most distant from the frictionless market paradigm so common in economic theory. We try to tackle this situation using a simple, although quite representative in practical terms, behavioral rule of wages. We will assume that, at the economy-wide market level, wages follow an adaptive rule that tracks the evolution of prices. The goal of the rule is to have the purchasing power of salaries aligned with prices. Since bargaining power is not complete, the wage rate usually lags behind prices when they rise but it keeps its value constant, in nominal terms, when they do not. Therefore, we assume the wage rate to be downward sticky or rigid. For the rest of markets, we will assume that exchange values adjust with no impediments to reproduce the given structure of the economy.

We examine the role of an eco-tax in this setting. The presence of a new tax on polluting activities will modify the whole set of exchange values since it will affect these activities' production costs. Additionally, the eco-tax will also change the level and composition of tax collections. Since the government uses its tax revenue to finance its activities, specifically the full set of social transfers (pensions, subsidies, labor compensation, etc.) to workers and their families, any tax-induced change in prices will also have an effect in the set of flows that define the income structure of the economy. Indeed, the government usually adjusts these income transfers to the evolution of prices to keep constant their perceived social value. Besides these price-indexing adjustments, the government may choose to use its newly found eco-tax collections to reduce the public deficit (from the augmented tax burden) or, alternatively, it may choose to preserve the initial tax burden by recycling the eco-tax collections into lower tax rates in other tax categories. The meta-studies in Maxim and Zander (2019) and Maxim (2020) summarize the scope of these environmental tax recycling policies and their degree of success in different case studies for actually enacted or for just simulated eco-tax policies.

The tax recycling approach has the advantage of keeping the size of the government constant in terms of its expenditures, combined tax revenues and public deficit. This policy option would be, quite naturally, the one causing the minimal distortion on the structure of the economy. However, some distortions, even if small, will persist. We will model any remaining distortion by scaling up or down the size of the economy while maintaining the basic structure as untouched as possible. This is the key to isolating price and quantity effects and it allows us to estimate price-induced income effects. These income effects, in turn, will drive the final consumption response and the corresponding adjustment in production levels. Technology wise, carbon emissions depend directly on production levels, and thus the link between eco-taxation policies and the subsequent carbon emissions. The proposed model therefore encompasses an economic side with an environmentally linked side and captures the eco-tax induced cost and income transmission mechanisms.

We select Spain in 2015 for this case study for two main reasons. The first reason is that eco-tax policies in Spain have been quite timid in the past and ample room for new tax policy initiatives do exist (OECD, 2019). In general, the implementation of eco-tax 
policies within the EU has not been stellar and just a few countries have taken up this policy tool in a limited way (Bosquet, 2000; OECD, 2019) and Spain is not one of them. Even without broad and active eco-tax policies, Spain's per capita emissions are slightly below the EU average whereas its carbonization index is slightly above (Padilla and Duro, 2013). Hence, room for improvement of environmental quality using eco-taxation tools exists and the possible effects of its adoption should be explored. The second reason, quite more pragmatic, is the availability of disaggregated interindustry and socio-economic data for 2015 which permits the convenient implementation of a multisectoral model that captures most of the active economic interactions.

In the next Section, we outline the main properties and novelties of the implemented interindustry model both in economic and environmental terms. In Section 3 we formulate the two eco-tax policy strategies and define the nature of the undertaken simulations whereas in Section 4 we present and discuss some of the results both in environmental and welfare terms to appraise the possibility of double benefits that would follow the adoption of the eco-tax policies. Section 5 concludes.

\section{Methodology}

\subsection{The production side}

We consider an interindustry economy with $i, j=1,2, \ldots, n$ economic sectors. We endow the economy with a productive technology that we represent by an $n \times n$ non-negative matrix $\mathbf{A}=\left(a_{j i}\right)$. The coefficients in matrix $\mathbf{A}$ represent the available technology and are calculated from the empirical data by dividing the level of intermediate input $j$ used in sector $i$ to produce its output (see Miller and Blair, 2009, Chapter 2). All commodities are at the same type inputs and outputs for the production process. We envision production as taking place in stages, which facilitates model description and improves model clarity. Labor $\mathbf{L}=\left(L_{j}\right)$ and capital $\mathbf{K}=\left(K_{j}\right)$ generate a non-produced composite input $\mathbf{V}=\left(V_{j}\right)$ in fixed proportions with input intensities $\left\{\ell_{j}: \kappa_{j}\right\}$. We call this composite good value-added. Value-added and materials, in turn, combine to produce domestic output $\mathbf{X}^{d}=\left(x_{j}^{d}\right)$ also in fixed proportions $\left\{a_{j i}: v_{j}\right\}$ whereas total output $\mathbf{X}=$ $\left(x_{j}\right)$ is the result of combining, domestic output and imports $\mathbf{X}^{m}=\left(x_{j}^{m}\right)$ once again using fixed proportions $\left\{\alpha_{j}^{D}: \alpha_{j}^{M}\right\}$. We therefore keep constant the structure of the economy assuming fixed technological proportions in all three of the productive stages:

$$
\begin{aligned}
& V_{j}=\operatorname{Min}\left(\frac{L_{j}}{\ell_{j}}, \frac{K_{j}}{\kappa_{j}}\right) \\
& x_{j}^{d}=\operatorname{Min}\left(\frac{x_{j i}^{d}}{a_{j i}}, \frac{V_{j}}{v_{j}}\right)
\end{aligned}
$$




$$
x_{j}=\operatorname{Min}\left(\frac{x_{j}^{d}}{\alpha_{j}^{d}}, \frac{x_{j}^{m}}{\alpha_{j}^{m}}\right)
$$

\subsection{The cost side}

We distinguish between basic and purchase prices. The basic price $p_{j}$ of a commodity includes the domestic production cost $c_{j}$ and the cost of the imported input measured by the current international price $p_{j}^{m}$. The domestic cost includes the cost of all material inputs and the cost of the incorporated value-added. Basic prices $p_{j}$ cover all unitary costs whereas purchase $q_{j}$ prices are basic prices augmented by a nontransferable valueadded tax vat $t_{j}$. Domestic production takes place under an indirect production tax $t_{j}$ whereas the use of labor in value-added conveys the payment of an industry payroll tax $s_{j}$. The full set of exchange values with the explicit role of all intervening taxes is:

$$
\begin{aligned}
& q_{j}=\left(1+v a t_{j}\right) \cdot p_{j} \\
& p_{j}=\alpha_{j}^{d} \cdot c_{j}+\alpha_{j}^{m} \cdot p_{j}^{m} \\
& c_{j}=\left(1+t_{j}\right) \cdot\left(\omega_{v} \cdot v_{j}+\sum_{i=1}^{n} a_{i j} \cdot p_{i}\right) \\
& \omega_{v}=\omega_{\ell} \cdot \ell_{j} \cdot\left(1+s_{j}\right)+\omega_{\kappa} \cdot \kappa_{j}
\end{aligned}
$$

In these expressions, $\omega_{v}$ represent the price index of the composite value-added input and $\omega_{\ell}$ and $\omega_{\kappa}$ represent the unitary prices of labor and capital services. Notice that all these expressions reflect the underlying unitary cost functions under fixed proportions.

\subsection{The dynamics of the wage rate}

We assume a simple adjustment rule for the wage rate that captures that workers negotiate with firms' representatives to keep the purchasing power of wages. We measure their degree of success by a coefficient $0 \leq \mu_{\omega} \leq 1$ with $\mu_{\omega}=0$ indicating no success in keeping up with the evolution of prices and $\mu_{\omega}=1$ showing full adjustment to changing prices:

$$
\omega_{\ell}=\omega_{\ell}^{0} \cdot \operatorname{Max}\left(1+\mu_{\omega} \cdot(C P I(\mathbf{q})-1), 1\right)
$$

In this expression $C P I$ represents a consumer's price index built upon purchase prices $\mathbf{q}$ $=\left(q_{j}\right)$ and $\omega_{\ell}^{0}$ is the initial wage rate. The volume of social transfers $m_{p}$ that families receive from the public sector follows the same type of adjustment rule. By analogy:

$$
m_{p}=m_{p}^{0} \cdot \operatorname{Max}\left(1+\mu_{m} \cdot(C P I(\mathbf{q})-1), 1\right)
$$


The adjustment coefficients $\mu_{\omega}$ and $\mu_{m}$ may respond to different formation rules although, typically, the public coefficient $\mu_{m}$ functions as the leading target for setting the private one $\mu_{\omega}$.

\subsection{The income side}

The production activities in the economy yield income to families. This income includes all receipts from the use of primary factors (labor $m_{L}$ and capital $m_{K}$ ) along with any social transfers $m_{p}$ from the public sector. This defines total income $m_{t}$. Since the labor income of employed families is subject to a personal payroll tax at rate $t_{h}$, their gross income $m_{g}$ is the result of detracting this payment from total income. In turn, disposable income $m_{d}$ is gross income minus labor and capital income taxes, which have different tax rates $t_{L}$ and $t_{K}$, reflecting an actual property of the tax system. Out of disposable income, families use a marginal propensity to consume $0<\delta<1$ to allocate a given fraction $m_{c}$ of their disposable income to finance consumption, with the remaining disposable income going straight to private savings. To wit:

$$
\begin{aligned}
& m_{t}=m_{L}+m_{K}+m_{p} \\
& m_{g}=m_{t}-t_{h} \cdot m_{L} \\
& m_{d}=m_{g}-t_{L} \cdot\left(m_{L}+m_{p}\right)-t_{K} \cdot m_{K} \\
& m_{c}=\delta \cdot m_{d}
\end{aligned}
$$

We keep the overall structure of final demand for consumption $\mathbf{c}=\left(c_{j}\right)$ using a fixed proportions demand scheme governed by non-negative weights $\theta_{j}$. Therefore, total consumption demand will scale up or down according to the level of expendable income $m_{c}$, which in turn depends on the accrued factorial and social transfers incomes, the personal tax rates for the different sources of income, and purchase prices $q_{j}$ :

$$
c_{j}=\frac{\theta_{j} \cdot m_{c}}{\sum_{i=1}^{n} \theta_{i} \cdot q_{i}}=\frac{\theta_{j} \cdot \delta \cdot\left(m_{L}\left(1-t_{h}-t_{L}\right)+m_{K}\left(1-t_{K}\right)+m_{p}\left(1-t_{L}\right)\right)}{\sum_{i=1}^{n} \theta_{i} \cdot q_{i}}
$$

At the same time, total factorial incomes $m_{L}$ and $m_{K}$ and social transfers $m_{p}$ will depend on factors' prices $\omega_{\ell}$ and $\omega_{\kappa}$ and the adjustments operating through the consumers' price index. Any shock modifying these prices, such as those ensuing from the adoption of an eco-tax, will have an effect of their levels. Hence, also in consumption demand.

\subsection{Eco-tax design and $\mathrm{CO}_{2}$ emissions}

The eco-tax $\mathbf{e c o}=\left(e c o_{j}\right)$ falls upon domestic production costs and we assume that the government defines its actual burden in proportion to total (i.e. direct and indirect) sectoral emissions of $\mathrm{CO}_{2}$. Let us denote the direct emissions coefficient of $\mathrm{CO}_{2}$ by $\mathbf{e}=$ 
$\left(e_{j}\right)$. We can calculate the overall level of emissions $E$ using the direct coefficients vector and the level of domestic production:

$$
E=\mathbf{e} \cdot \mathbf{X}^{d}
$$

Using matrix A we compute the multiplier matrix $\mathbf{L}$ :

$$
\mathbf{L}=(\mathbf{I}-\mathbf{A})^{-1}
$$

From here, the total (direct plus indirect) coefficient vector $\lambda$ of emissions is obtained from:

$$
\lambda=\mathbf{e} \cdot \mathbf{L}
$$

This vector allows us to order all sectors by their total emissions coefficients. We then calibrate the eco-tax scheme so that it satisfies that eco is proportional to the vector $\lambda$ and, moreover, has the same collection capacity that a given homogenous eco-tax which the government uses to set a tax collection target.

The introduction of an eco-tax on the domestic component of production costs would modify the equation for basic prices. Combining expressions (2.2) and (2.3) yields:

$$
p_{j}=\left(1+e c o_{j}\right) \cdot\left(\alpha_{j}^{d} \cdot\left(1+t_{j}\right) \cdot\left(\omega_{v} \cdot v_{j}+\sum_{i=1}^{n} a_{i j} \cdot p_{i}\right)\right)+\alpha_{j}^{m} \cdot p_{j}^{m}
$$

All basic and purchase prices will readjust to the new tax whereas the wage rate and social transfers will track down the change in prices and incorporate it into the system with a double effect. On the one hand, there is an additional push on prices through the wage rate; on the other hand, factorial labor income and social transfers also change and, as a result, we need to rescale consumption demand. We measure the effects on domestic output using the multiplier matrix $\mathbf{L}$ :

$$
\Delta \mathbf{X}^{d}=\mathbf{L} \cdot \Delta \mathbf{c}
$$

From here we can now evaluate changes in total emissions levels post eco-tax by:

$$
\Delta E=\mathbf{e} \cdot \Delta \mathbf{x}^{d}=\mathbf{e} \cdot \mathbf{L} \cdot \Delta \mathbf{c}
$$

\subsection{The welfare side}

The eco-tax will modify prices. Since we keep the whole structure of the economy as unaltered as possible, except for the income rescaling and its derived effect on consumption demand, there are no substitution effects. The rescaling only generates income effects. Hence, all the welfare consequences will be exclusively income related. This allows us to eliminate the price-induced substitution effects in the calculation of the mitigation effects on $\mathrm{CO}_{2}$ emissions. Therefore, all the derived changes will be pure volume effects within the given structure of production and consumption. Likewise, given the absence of smooth convex utilities, we need not refer to the usual Hicksian welfare measures nor in fact to any explicit utility function. We use instead Slutsky's definitions that need not an optimal expenditure function. With no substitution in 
consumption, it is possible to show that Slutsky's equivalent and compensating variations coincide. Hence, we can measure the money metric change in welfare $W$ brought about by the eco-tax by:

$$
\Delta W=g\left(\mathbf{q}^{1}, m_{c}^{0}\right)-g\left(\mathbf{q}^{0}, m_{c}^{0}\right)=g\left(\mathbf{q}^{1}, m_{c}^{0}\right)-m_{c}^{0}
$$

In this expression, the index " 1 " refers to the post eco-tax situation and the index " 0 " to the initial situation. The function $g\left(\mathbf{q}, m_{c}\right)$ measures the incurred expenditure level at the vector of purchase prices $\mathbf{q}$ and income level $m_{c}$.

\subsection{The chain of events}

The following scheme reproduces in a sequential way the main chain of events and set of repercussions that the model tries to capture. In fact, we know that the determination of all variables is simultaneous but it is always helpful to visualize the chain stepwise:

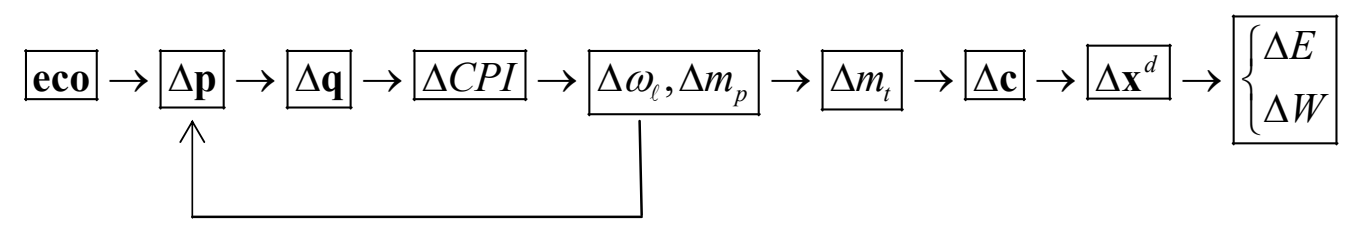

The environmental tax eco in the beginning of the chain triggers changes in basic and purchase prices that end up affecting the consumer price index $C P I$ which, through the adjustment process in wages and public transfers, give rise to an impact in consumption demand and domestic production levels. From here, and at the end of the chain, the model allows us to evaluate the induced change in $\mathrm{CO}_{2}$ emissions and in money metric welfare once all the ripple effects have accumulated.

\section{Simulations}

We use input-output and National Accounting income data published by the National Institute for Statistics (INE: http://www.ine.es) for the Spanish economy in 2015. We rearrange the data using the Social Accounting Matrix $(S A M)$ framework. The novelty of this $S A M$ is that it distinguishes between basic valued and purchase valued final transactions. Thanks to the distinction, we can calculate separately basic and purchase prices as defined in expressions (2). We calibrate the model's parameters in technology and demand (expressions (1) and (5)) to derive unitary basic prices and factor prices. The calibration methodology entails using the standard normalization in CGE and interindustry modeling by which all the selected units have exactly the value of one Euro. This normalization solves the problem that reported monetary values in inputoutput data do not distinguish the physical and the currency unit parts (see Cardenete et al, 2016, Chapter 6, for technical details in calibration issues).

We approximate both adjustment coefficients $\mu_{\omega}$ and $\mu_{m}$ with a single value $\mu$ that we obtain from data published by the Spanish National Institute for Statistics (INE, 2014) that shows that, in general, salaries' growth lags behind price increases measured by the consumer's price index $C P I$. We take the value $\mu=0.8$ as a reasonable approximation to 
the data. Information on estimated sectorial emissions of $\mathrm{CO}_{2}$ (in equivalence units) for 2015 comes from the environmental database compiled by the National Institute for Statistics. We use these emissions along with sectorial domestic output to calculate the direct emissions coefficients e.

We consider two possible policies regarding the eco-tax. First, we evaluate its effects when wages adjust partially and the government uses the accrued eco-tax collections to reduce the public deficit. However, this scenario changes the size of the government in terms of its increased tax revenue and introduces a distortion in the structure of the economy. Second, we eliminate this distortion by recycling the new tax collections to reduce labor payroll taxes, both the industry and the personal rates. The size of the government remains essentially constant in terms of aggregate expenditure and tax collections, hence in its deficit too, except for the partial value adjustment in social transfers (through expression 3.2). Therefore, we need to compute the neutral reduction in the payroll tax rates that would offset the increased collection capacity of the eco-tax. This approach is the most common one for revenue recycling (Maxim and Zander, 2019). Notice that we select the level of fixed revenue in nominal terms since the government cannot foresee the endogenous change in the CPI. Hence, real tax revenues will differ ex-post from the nominal target. Simply stated, the government observes its current tax collections and it fixes the observed (nominal) base as its constant target.

We calculate the specific eco-tax rates running first an auxiliary simulation with a homogeneous and common sectorial rate of 1 percent. We determine the tax collections under the common rate and then we re-dimension the sectorial rates in proportion to the total $\mathrm{CO}_{2}$ footprint using the total emissions multiplier vector $\lambda$ (expression (8)) but at the same time keeping the target eco-tax revenue constant. The non-homogeneous ecotax rates play two roles. In the short run, higher emitters of $\mathrm{CO}_{2}$ receive higher tax rates and their tax burden reflect their contribution to total emissions; in the long run this assignment of tax rates should work to incentivize the use of less polluting technologies either through price-driven input substitution or through the adoption of more efficient production recipes (Rose, 1983). The current model does not capture these long run issues, for they require an altogether different modeling platform, especially because under these two situations the economy would undergo structural change.

We solve the model using GAMS under a discontinuous non-linear programming algorithm $^{1}$ that deals with the non-smooth expressions (3). The solver computes all prices, income levels, emissions and welfare. Since the wage rate is endogenous, we use the price of capital services as numéraire. All value magnitudes are normalized ex-post using the CPI. This ensures that we can compare real magnitudes (based upon their purchasing power) after all endogenous adjustments take place (see Guerra and Sancho, 2018, and Guerra et al, 2019).

\section{Results and discussion}

\footnotetext{
${ }^{1}$ We use CONOPT as the default solver and the algorithm DNLP available within CONOPT.
} 
Figure 1 and Tables 1 through 4 summarize the main results that the current model produces. In Figure 1 we visualize the vectors of direct $\mathbf{e}$ and total $\lambda$ emission coefficients of $\mathrm{CO}_{2}$ for the classification of $n=30$ sectors that we use in the data. Name descriptions appear in the headings. Notice that out of the 30 sectors only 5 of them have significant direct coefficients above the mark 0.40 .

[Figure 1 around here]

We consider two main simulations. In the simulation labeled as "No tax recycling", the government sets up the eco-tax on top of the current tax system. Total tax revenue increases and the government just uses it to correct the public deficit. In contrast, in the "tax recycling" simulation, the government fine-tunes the rates of the two payroll taxes to keep total tax revenue unchanged. In both simulations the wage rate and social transfers partially adjust to the new eco-tax induced changes in purchase prices through the coefficient $\mu=0.8$.

In Table 1, we present the income results that would follow under the two simulations next to benchmark data for ease of comparison. As expected, in the no-recycling scenario all income levels fall in real terms. The eco-tax erodes the purchasing power of all sources of private income and income adjustments working through the CPI cannot keep track with the erosion. When the eco-tax revenue is recycled, however, gross, disposable and expendable income all increase even though total income falls in real terms. The reduction in the personal payroll tax $t_{h}$, that directly affects private labor income (expression 4.2), explains this fact. At the same time, the reduction of the industry payroll tax rates $s_{j}$ lowers the pressure on prices and yields a lower $C P I$. Hence, the effect of the lower $C P I$ also helps in reducing the losses in real income levels.

[Table 1 around here]

We display the corresponding tax collections, again in real terms, in Table 2. Recall that we calculated the eco-tax rates using as a target the accrued tax collection of a 1 percent homogeneous tax rate on domestic production costs. We then preserve this level of revenue but assign individual tax rates according to each sector total $\mathrm{CO}_{2}$ footprint. In aggregate terms, the eco-tax would represent a burden of a bit over 5 percent of all tax revenues in both simulations ( 5.1 and 5.3 percent, respectively). In the tax recycling case, lower payroll taxes would compensate for the increased eco-tax burden. This compensating reduction in rates would be about 15.5 percent. Taken together, the load of all payroll taxes, should they be reduced by 15.5 percent, would fall from being 36.7 percent of the total burden in the no tax recycling case to being 32.8 percent in the tax recycling case - close to four percent points less. The effect on the rest of taxes (income and sales taxes) seems to be slightly detrimental but quantitatively unimportant in value.

[Table 2 around here]

In Table 3, we show the effects of the eco-tax in terms of $\mathrm{CO}_{2}$ emissions and welfare and allows us to consider them in terms of a possible double dividend. In the no tax 
recycling simulation, we observe that the effect of the eco-tax is a reduction in the total volume of $\mathrm{CO}_{2}$ emissions of 1,429 million of metric tons, just a fall of 0.51 percent over the benchmark level. Since the (average) eco-tax is 1 percent, this 0.51 value also corresponds to the empirical elasticity response in this tax scenario. Given the linear nature of the interindustry model, any proportioned increase in the eco-tax rate would imply the same type of response in emissions reduction. We should therefore expect that an (average) 2 percent eco-tax would reduce emissions in about 1 percent, or 2,858 million of metric tons, and so on. The reduction in incomes that we detected in Table 1 takes the form of a welfare loss here in Table 3. The welfare cost, measured by Slutsky's equivalent variation, would amount to 7,566 million of Euros. The additional level of expendable income $m_{c}$ that, in percent, would offset the estimated welfare loss would be 1.26 percent over the initial level of expendable income. This figure indicates the level of erosion in the purchasing power of families, even when we incorporate adjustments in income levels that track down the evolution of purchase prices. We do not observe a double dividend: emissions fall but welfare falls as well.

[Table 3 around here]

The opposite happens when the government keeps the nominal size of its revenue constant. In this case, it is feasible to reduce the rates of the payroll taxes. As we already observed in Table 1, disposable and expendable income would tend to increase. The specific effect detected here is that emissions would in fact rise, even if the change turns out to be small. Families would now be better off as the positive EV indicates. We can estimate the money metric welfare increase in 1,247 million of Euros and the compensating reduction in income would be now small but negative. In other words, this new income in the hands of families, liberated by the payroll tax reduction, would boost their consumption demand, in turn driving output and emissions upwards through the multiplier matrix L. Once again, we do not observe a double dividend. Families are better off but the environmental quality of the economy deteriorates as emissions increase. As before, linearity is again useful in this second scenario to gauge the effects of the same policy under different, but proportioned, eco-tax parameters.

The role of the adjustment parameter $\mu$ on the wage rate seems to be less intense than the decision on the type of tax policy. In Table 4, we compare the central assumption $(\mu=0.8)$ with the emissions and welfare changes in two extreme cases-indeed, not very realistic - that correspond to no adjustment whatsoever $(\mu=0)$ and full adjustment $(\mu=1)$.

[Table 4 around here]

Higher values of the parameter $\mu$ give rise to less erosion in welfare capturing the fact that the wage rate would command higher levels of income. Similarly, the reduction in emissions appears to be inversely related to this parameter. In none of the above six cases we detect the possibility of a double dividend; only under the empirically unrealistic assumption that the wage rate does not adjust at all but the tax burden 
remains constant we would observe a fall in emissions, which is almost negligible, and an also small fall in welfare. Thus, the type of implemented tax policy seems to be quite more determinant in the evaluated results than the value of the adjustment parameter in the wage rate.

\section{Conclusions and implications}

We have explored the reach and limits of eco-taxation using a simple interindustry model in which we keep the structure of the economy with the minimal possible alterations. The conceptual novelty of the model is that it breaks the classical dichotomy by linking prices and quantities through income adjustments. We compute the set of prices that keeps most of the same economic structure working after the government levies a new tax on $\mathrm{CO}_{2}$ emitters. We depart from the typical neoclassical determination of the wage rate and assume that it is determined through wage negotiations. These negotiations are successful only in part, reflecting the distributional frictions that commonly occur between labor and capital. True enough, real-world situations encompass many more explanatory factors than models can successfully accommodate. Models, though, have the ability to isolate some of these factors and ascertain their specific impact. The model we use isolate the wage rate and makes it endogenous following a partial adjustment rule. If prices rise, so does the wage rate, but if prices fall then it is downward rigid and remains at the initial value. We examine this behavior of the wage rate under two alternative tax policies. Inasmuch as we keep unaltered the remaining structure of the economy, we are able to visualize and quantify the role played by the dynamics of the wage rate and the tax policy strategies on carbon emissions and private welfare.

Under our assumptions, we cannot conclude that a double dividend will occur. Either the tax policy (first scenario with no tax recycling) improves environmental quality but erodes welfare, or the results become reversed and welfare improvements go along with lower environmental quality (second scenario with neutral tax recycling). This result, namely that an eco-tax policy may end up achieving the opposite of what was intended, runs contrary to intuition, or at least to partial equilibrium based intuition. Hence, the relevance of studying the issue under an approach that accounts for both direct and indirect outcomes. In our case, tax revenue recycling boosts private expendable income, which increases final demand, gross output and emissions. The design of the policy would be incomplete, and possibly erroneous, if we do not take into account and measure its possible repercussions.

In the tax recycling simulation we see that the payroll tax would be reduced. In a fully general CGE model with smooth production functions this reduction would be an incentive for firms to substitute capital for labor. We rule out this possibility in the analysis since we want to keep the structure of the economy under the minimal set of distortions. The reason is the desire to isolate income driven effects from price induced substitution effects and identify their responsibility for the possible double benefits of eco-tax policies. 
Recall also that the results we calculate eliminate all substitution effects in consumption since we do not use any smooth utility function. Hence, households' consumption does not respond to changing prices, only to price induced changes in income levels. This is no doubt a limitation but has the advantage of unmingling income and substitution effects and offers an appraisal unbiased by the workings of the latter. The standing assumption is perhaps that the observation of a double dividend would be likelier under strong substitution effects that, guided by adequately designed eco-taxation, divert final demand and production from intense emitters to more eco-friendly activities. The testing of this assumption requires, minimally, a non-linear modeling approach that is capable of dealing with both smooth utilities and smooth production frontiers.

We must also mention that we do not consider distributional issues since our database use the single representative consumer assumption and thus we do not distinguish families by socioeconomic characteristics. This is a limitation of the current database that does not allow us to examine who would gain or lose in welfare relative terms from the examined policies.

Finally, the eco-tax policies we have looked at work exclusively in a pure public finance basis. We have not examined, for instance, the effects of recycling tax receipts to finance and foster expenditure policies that could promote environmental efficiency gains via new technologies or alternative goods and services. The model we use is static in nature and this type of positive dynamic change effects cannot be studied within its current framework.

Acknowledgements: I would like to acknowledge support from research project MICINNECO2017-85534P.

\section{References}

Bardazzi, R. (1996) Reduction in Social Security contributions: which alternatives for financing coverage? Economic Systems Research 8(3):247-270.

Bosquet, B. (2000) Environmental tax reform: does it work? A survey of the empirical evidence. Ecological Economics 34:19-32.

De Souza, KB., L.C. de Santana and F.S. Perobelli (2016) Reducing Brazilian greenhouse emissions: scenario simulations of targets and policies. Economic Systems Research 28(4):482-496.

Freire, J. and M.S. Ho (2019) Carbon taxes and the double dividend hypothesis in a recursive-dynamic CGE model for Spain. Economic Systems Research 31(2):267284. 
Fullerton, D. and E. Muehlegger (2019) Who bears the economic burden of environmental regulations? Review of Environmental Economics and Policy 13(1):62-82.

Gemechu, E.D., I. Butnar, M. Llop and F. Castells (2014) Economic and environmental effects of $\mathrm{CO} 2$ taxation: an input-output analysis for Spain. Journal of Environmental Planning and Management 57(5):751-768.

Guerra, A.I and F. Sancho (2018) On the need to compensate the compensating variation in CGE modeling. Economic Systems Research 30(3):313-322.

Guerra, A.I., A. Manresa and F. Sancho (2018) The true index of cost of living under general equilibrium: the numéraire matters. Economic Letters 173:69-72.

INE (2014) Boletín Informativo del Instituto Nacional de Estadística, n.8.

Kiuila, O., A. Matkandya and M. Scasny (2019) Taxing air pollutants and carbon individually or jointly: results from a CGE model enriched by an emission abatement. Economic Systems Research 31(1):21-43.

Llop, M. and L. Pié (2008) Input-Output analysis of alternative policies implemented on the energy activities. Energy Policy 36:1642-48

Maxim, M.R. and K. Zander (2019) Can a green tax reform entail employment double dividend in European and non-European countries? A Survey of the empirical evidence. International Journal of Energy Economics and Policy 9(3):218-228.

Maxim, M.R. (2020) Environmental fiscal reform and the possibility of triple dividend in European and non-European countries: evidence from a meta-regression analysis. Environmental Economics and Policy Studies, https://doi.org/10.1007/s10018-020$\underline{00273-8 .}$.

Miller, R.E and P.D. Blair (2009) Input-Output Analysis: Foundations and Extensions, Second edition, New York: Cambridge University Press.

OECD (2019), Taxing Energy Use 2019: Using Taxes for Climate Action, OECD Publishing, Paris, https://doi.org/10.1787/058ca239-en.

Padilla, E. and J.A. Duro (2013) Explanatory factors of CO2 per capita emission inequality in the European Union. Energy Policy 62:1320-1328.

Roland-Holst, D. and F. Sancho (1995) Modeling prices in a SAM structure. The Review of Economics and Statistics 77(2):361-371.

Rose, A. (1983) Technological change and input-output analysis: an appraisal. Socio Economic Planning Sciences 18(5):305-318. 
Shoven, J.B and J. Whalley (1984) Applied General Equilibrium models of taxation and international trade: An introduction and survey. Journal of Economic Literature 22: 1007-1051.

Sraffa, P. (1960) Production of commodities by means of commodities, Cambridge: Cambridge University Press.

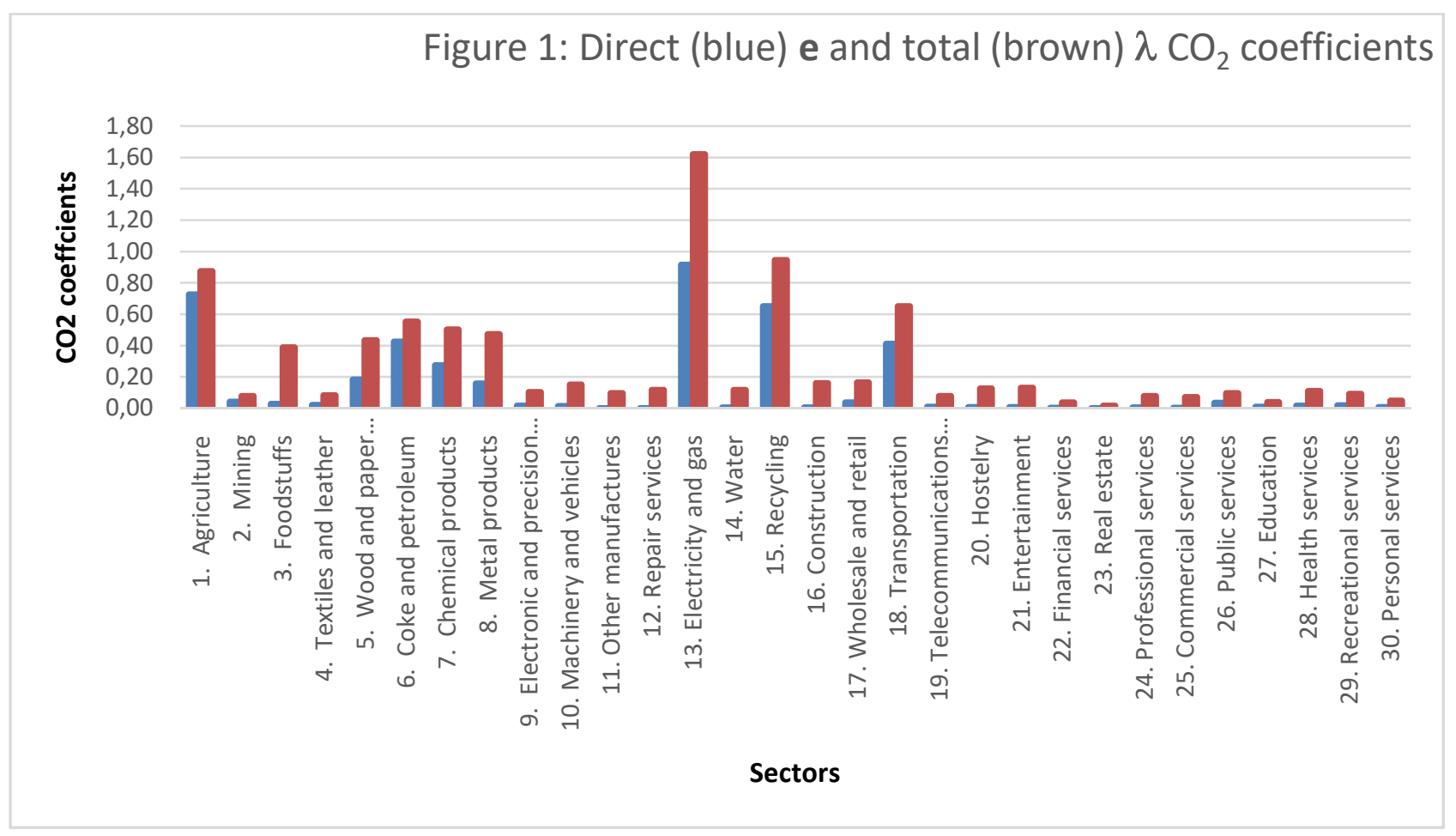

\begin{tabular}{|l|r|r|r|}
\hline \multicolumn{1}{|c|}{$\begin{array}{c}\text { Table 1: Income levels } \\
(\text { millions of } € \text { ) }\end{array}$} & \multicolumn{1}{c|}{$\begin{array}{c}\text { Benchmark: } \\
C P I=1\end{array}$} & $\begin{array}{c}\text { No tax recycling: } \\
C P I=1.0220\end{array}$ & \multicolumn{1}{c|}{$\begin{array}{c}\text { Tax recycling: } \\
C P I=1.0074\end{array}$} \\
\hline Labor income $m_{L}$ & 410,583 & $408,815(-0.43 \%)$ & $409,983(-0.15 \%)$ \\
Capital income $m_{K}$ & 453,464 & $443,703(-2.15 \%)$ & $450,153(-0.73 \%)$ \\
Social transfers $m_{p}$ & 170,583 & $169,849(-0.43 \%)$ & $170,334(-0.21 \%)$ \\
Total income $m_{t}$ & $1,034,630$ & $1,022,367(-1.18 \%)$ & $1,030,470(-0.40 \%)$ \\
Gross income $m_{g}$ & 993,618 & $981,5328(-1.21 \%)$ & $995,868(0.33 \%)$ \\
Disposable income $m_{d}$ & 876,130 & $865,287(-1.24 \%)$ & $877,923(0.20 \%)$ \\
Expendable income $m_{c}$ & 605,743 & $598,246(-1.24 \%)$ & $606,983(0.20 \%)$ \\
\hline
\end{tabular}




\begin{tabular}{|l|r|r|r|}
\hline \multicolumn{1}{|c|}{$\begin{array}{c}\text { Table 2: Tax revenue } \\
\text { (millions of } € \text { ) }\end{array}$} & \multicolumn{1}{c|}{$\begin{array}{c}\text { Benchmark: } \\
C P I=1\end{array}$} & $\begin{array}{c}\text { No tax recycling: } \\
C P I=1.0220\end{array}$ & $\begin{array}{c}\text { Tax recycling: } \\
C P I=1.0074\end{array}$ \\
\hline Eco-tax & 0 & 20,095 & 20,075 \\
Personal payroll tax & 41,012 & 40,835 & 34,602 \\
Industry payroll tax & 103,871 & 103,424 & 87,636 \\
Rest of taxes & 230,735 & 229,040 & 230,562 \\
Total tax revenue & 375,618 & 393,394 & 372,875 \\
\hline
\end{tabular}

Payroll taxes reduction: $15.5 \%$

\begin{tabular}{|l|r|r|r|}
\hline \multicolumn{1}{|c|}{ Table 3: Double dividend? } & Benchmark & No tax recycling & \multicolumn{1}{c|}{ Tax recycling } \\
\hline Emissions (millions of MT) & 279,731 & 278,302 & 279,967 \\
Percentage change & & $-0,51 \%$ & $0.08 \%$ \\
Welfare change (EV) & & $-7,566$ & 1,247 \\
Compensating income & & $1.26 \%$ & $-0.21 \%$ \\
\hline
\end{tabular}

\begin{tabular}{|l|rcc|ccc|}
\hline $\begin{array}{c}\text { Table 4: Sensitivity to } \\
\text { parameter } \mu\end{array}$ & \multicolumn{3}{|c|}{$\begin{array}{c}\text { No tax } \\
\text { recycling }\end{array}$} & \multicolumn{3}{c|}{ Tax recycling } \\
\hline & $\mu=0$ & $\mu=0.8$ & $\mu=1$ & $\mu=0$ & $\mu=0.8$ & $\mu=1$ \\
\cline { 2 - 8 } & $-0.64 \%$ & $-0.51 \%$ & $-0.46 \%$ & $-0.01 \%$ & $0.08 \%$ & $0.11 \%$ \\
Emissions change in \% & $-9,702$ & $-7,566$ & $-6,844$ & $-0,070$ & 1,247 & 1,673 \\
Welfare change (EV) & & & & & &
\end{tabular}

